\title{
EZB Diffuse Large B-Cell Lymphoma
}

National Cancer Institute

\section{Source}

National Cancer Institute. EZB Diffuse Large B-Cell Lymphoma. NCI Thesaurus. Code C148398.

A diffuse large B-cell lymphoma molecular subtype characterized by the presence of EZH2 gene mutations and BCL2 gene translocations. Patients who belong in this subtype have a favorable outcome. (NEJM 2018; 378: 1396-407) 